\title{
26th European Congress of Arachnology in Midreshet Ben-Gurion
}

Early in September, 130 arachnologists and 11 accompanying persons from 27 countries from all over the world headed to Israel to attend the $26^{\text {th }}$ European Congress of Arachnology hosted by the Jacob Blaustein Institutes for Desert Research.

From $4^{\text {th }}$ to $8^{\text {th }}$ September, the centre of European arachnology was at the Sede Boqer Campus of the Ben-Gurion University of the Negev at Midreshet Ben-Gurion. Four plenary speakers informed the audience about the scorpion tree of life (Lorenzo Prendini), spider-insect interactions from visual perspectives (I-Min Tso), dispersal behavior in spiders from disturbed landscapes (Sara Goodacre), and how sexual selection and ecology shape plastic development of spiders (Maydianne Andrade). Eighty oral presentations and 44 poster dealing with all aspects of arachnid biology, such as new challenges for arachnid systematics, physiology and biochemistry, or behavioural ecology, provided insights into the current state of arachnological science.

Historical aspects were covered as well as future prospects. For example, Yuri Marusik gave a chronological review of spider classification schemes while Peter van Helsdingen talked about the future of "Fauna Europaea". Christian Kropf revived the old question "how do orb-weaving spiders avoid getting stuck in their own capture thread?" whereas Boris Leroy reported on the future distribution of a threatened spider with respect to climate change. Generally, spiders clearly took centre stage comprising more than $90 \%$ of the contributions, especially those presented by behavioural ecologists. However, some lectures and posters on scorpions, harvestmen, camel spiders and ricinuleids increased the diversity of presentations. Jason Dunlop even mentioned mites, though in connection with solifugids. Moreover, Rudy Jocqué had the courage to show the arachnological audience the "most shocking slides ever seen". doi: $10.5431 /$ aramit4213 Besides the interesting and informative scientific program, the excursions and social events also deserve closer attention. On the first evening, a reception near the tombs of David Ben Gurion and his wife offered additional historical information, along with a breathtaking view of the sunset over the Negev. The traditional 'Russian Party' provided the opportunity to savour Russian snacks, like smoked fish and caviar, and international spirits. On Monday evening, an Israeli meal and a 'Desert at night'-walk was on the program. Naturally this walk was focused on scorpion collecting. Tuesday, $6^{\text {th }}$ September, was the excursion day. Participants could choose among three tours. The historic tour included a visit to the archaeological site of Avdat in the Negev Highlands and to a reconstructed Nabatean farm - a UNESCO world heritage site. The nature tour included a collecting trip
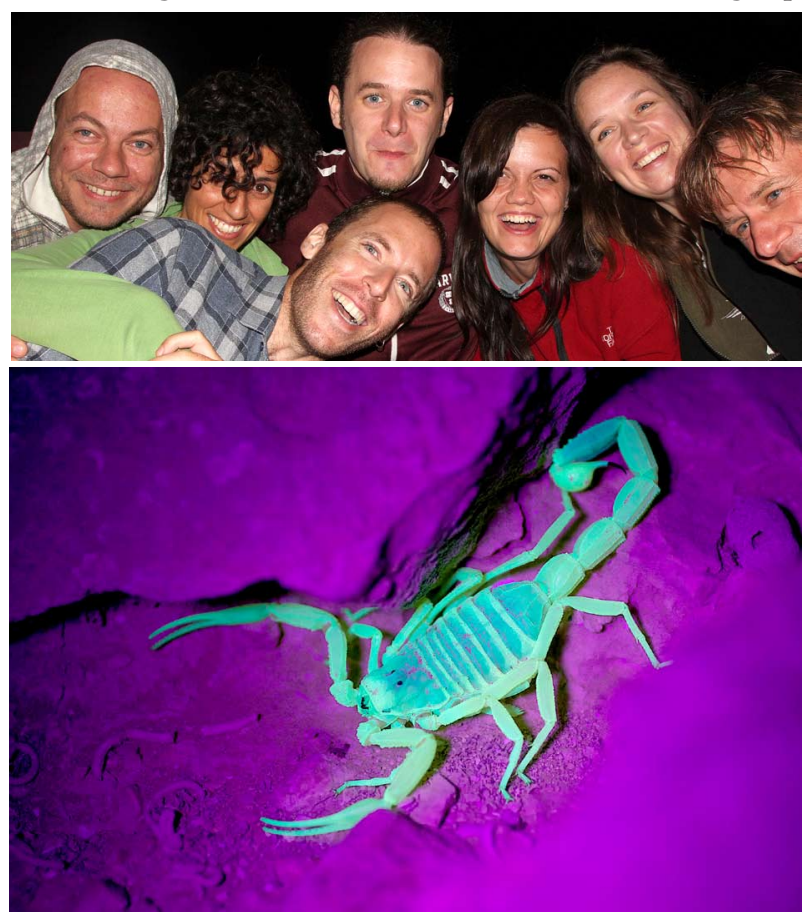

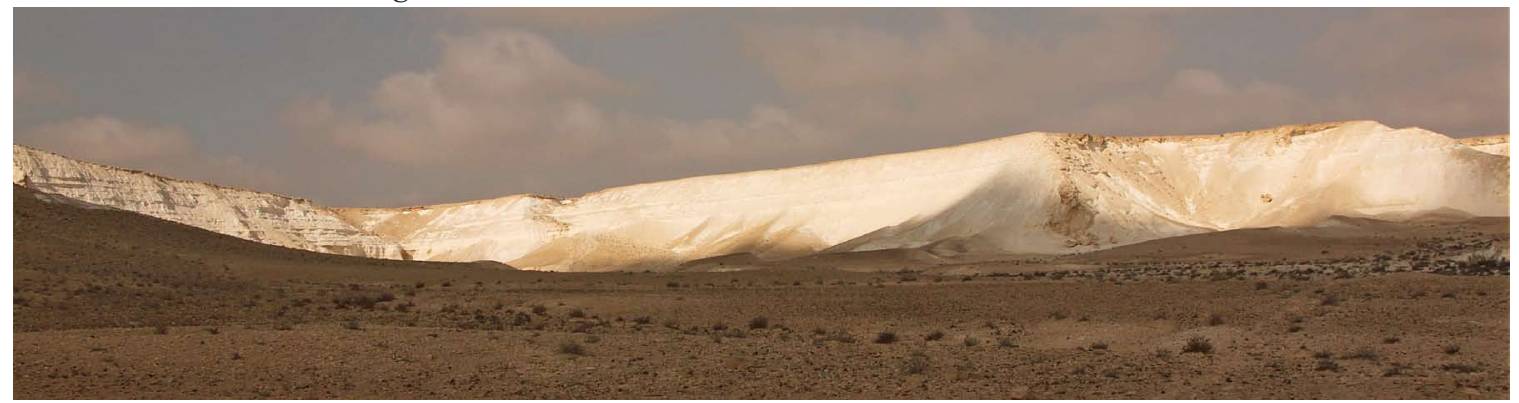




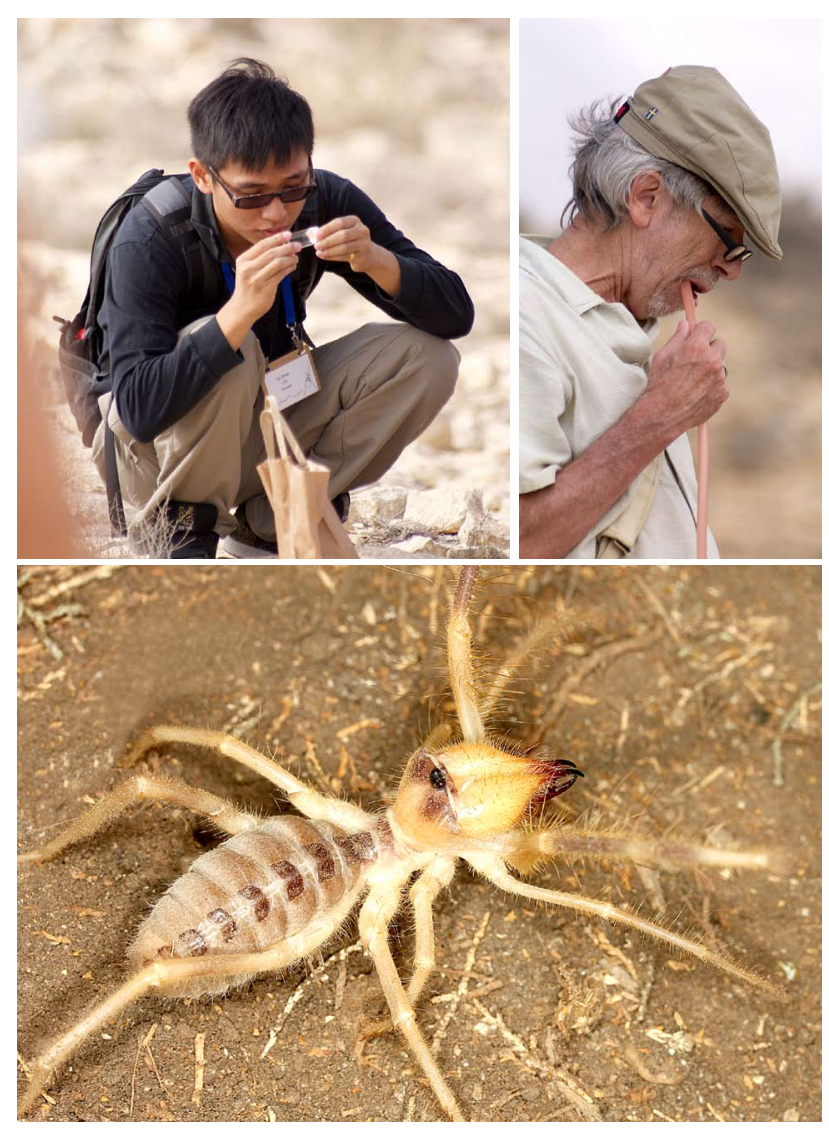

to the Negev Highlands and a guided hike in the Ein Avdat National Park, and a natural oasis in the Zin Canyon. The adventurous hiking tour led participants through the Zin Canyon to the oasis of Ein Aqev. After lunch, all groups were briefly introduced to the work of the Ramat Negev Agricultural R\&D Station. In the afternoon, participants could relax at a local desert spa or spend some free time at Midreshet Ben-Gurion. Excursions and desert walks provided a unique opportunity to marvel at the gorgeous landscape and to collect scorpions (e.g. Leiurus quinquestriatus, Buthus occitanus, Scorpio maurus), spiders (e.g. Stegody-

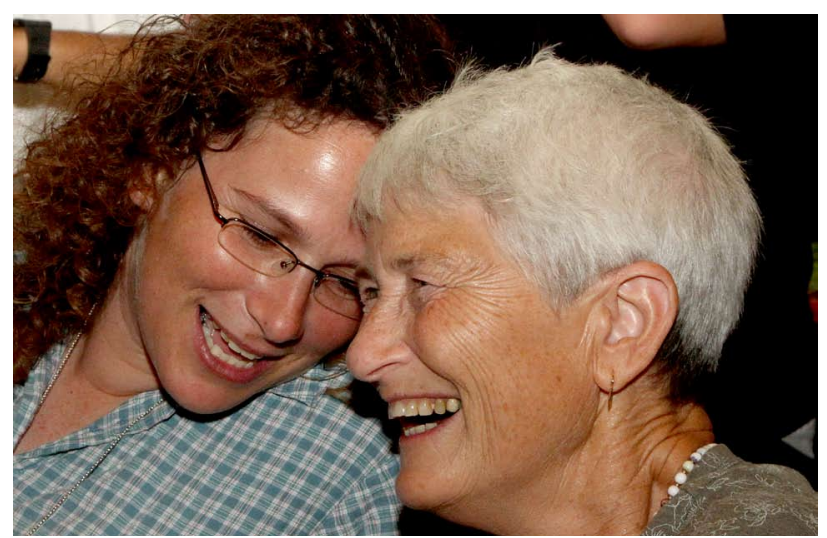

phus, Latrodectus) or camel spiders (e.g. Galeodes sp.). In the evening, the last destination was not infrequently the 'Isopod', where the arachnologists enjoyed one or more Israeli beers.

The Congress Gala Dinner took place on Wednesday evening as a Bedouin-style dinner, followed by a very special entertainment that taught us that Salticidae are not the only jumping animals in Australia... However, it did not take long until the arachnological audience was playing with remarkable musical instruments and dancing to local rhythms.

The General Meeting of the ESA members closed the congress on Thursday evening and finally, 16 student prizes were awarded. First prizes were given to Chao-Chia Wu (European Society of Arachnology), Miriam Schaider (Arachnologische Gesellschaft, oral), Alberto Chiarle (Arachnologische Gesellschaft, poster), Boris Leroy (Yale University Press, oral), Christina Holm (Oxford University Press, oral), Chen-Pan Liao (Oxford University, poster), Ren-Chung Cheng (Cambridge University Press, oral), and $\mathrm{Mu}$-Yun Wang (Cambridge University Press, poster).

Finally, those who still had some time left enjoyed the opportunity to attend a post congress tour and visit the Judean Desert, the Dead Sea and Jerusalem - and again the opportunity to collect arachnids.

The excellent organization, interesting contributions and the beautiful landscape of the Negev characterized the $26^{\text {th }}$ European Congress of Arachnology. Finally, we would like to thank Yael Lubin, Efrat Gavish-Regev, the organizing committee and the scientific committee for their great work. We really enjoyed these days in Israel and we are already looking forward to the $27^{\text {th }}$ Congress of Arachnology in Ljubljana in September 2012 (http://ezlab.zrc-sazu.si/eca2012).

Miriam Schaider

Photos: Impressions from the congress tours; $\mathbf{p 6 0}$ top 'Negev by night' - enlighted by the smiles of some nightly-active arachnologists; middle - Buthus occitanus 'glowing' greenish under the light of the blacklight-torch; bottom - Scenery from the adventurous hiking tour at our congress-excursion to the Negev; p61 top - Tai-Shen Lin (I.) and Robert Bosmans (r.) during the collecting tour; middle - Solipugids, like this big Galeodes could be found under stones; bottom - Relaxed and happy, our kind chief organizers Efrat Gavish-Regev (I.) and Yael Lubin (r.); photos by C. Komposch \& D. Cordes. 